\title{
Assessing the Safety Factors of Ship Berthing Operations
}

\author{
Wen-Kai Kevin Hsu \\ (National Kaohsiung Marine University, Kaohsiung, Taiwan) \\ (E-mail: khsu@webmail.nkmu.edu.tw)
}

\begin{abstract}
The purpose of this paper is to discuss the safety of ship berthing operations in port. Based on the features of ship's berthing operations and relevant literature, the Safety Factors (SFs) of ship berthing at docks are first investigated. A Safety Index (SI) with a Fuzzy Analytic Hierarchy Process (AHP) model is then proposed to assess those SFs from port marine pilots, by which port managers and ship carriers may make policies to improve ship berthing safety. To validate the model, berthing operations at Kaohsiung Port in Taiwan were empirically investigated. The results indicate the main safety factors affecting ship berthing at port docks are: working concentration, the condition of mooring lines, emergency response, port policy of improving business and berth length. Based on those results, the theoretical and managerial implications for ship berthing safety at dock are finally discussed.
\end{abstract}

\author{
KEY WORDS

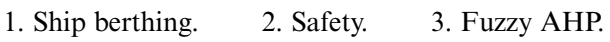

Submitted: 6 August 2014. Accepted: 18 November 2014. First published online: 17 December 2014.

1. INTRODUCTION. Recently, in line with increasing global trading activities, shipping companies are continuing to build ever larger vessels for shipping markets. The ships in the world, therefore, are not only becoming faster and larger, but also rapidly increasing in quantity. Under restricted shipping lanes, a growing number of vessels may lead an increased likelihood of maritime accidents (Hsu, 2012).

Generally, a ship accident may result in an expensive loss. The most common damage caused by a ship accident includes human casualties, port facility damage, cargo damage and vessel damage. In practice, those damages may harm the reputations of shipping carriers and port companies, which may lead to decreased business. A ship accident in port may cause fuel or cargo oil leakage, leading to port pollution. Since the losses from a ship accident can be enormous, many port authorities in the world have paid attention to reducing the incidence of ship accidents in port (Debnath et al., 2011).

Practically, common ship accidents include collisions and grounding, in which collisions are the most frequent maritime accident (Debnath and Chin, 2010; Hsu, 2012). In practice, collisions most commonly occur when ships berth. Thus, to 
reduce ship accidents, issues related to ship berthing safety should be considered. Unfortunately, in the relevant literature, there is a lack of studies on such topics.

The purpose of this paper is to discuss the safety of ship berthing operations in port. Based on the relevant literature and the features of ships' berthing operations, the Safety Factors (SFs) of ship berthing are first investigated. Since, ship berthing safety is a highly professional issue, a Safety Index (SI) based on a Fuzzy Analytic Hierarchy Process (AHP) model is then proposed to assess those SFs. The Safety Index consists of two weights, the SFs' importance weight and frequency weight. The former is defined as the effect of a SF in causing a ship accident, while the latter is explained as the frequency of the SF causing a ship accident. In practice, the former depends on the SF's features, and the latter depends on the performance of port management. In the relevant literature, most studies only focus on the former (e.g. Lu and Tsai, 2008; Hsu, 2012). Based on the Safety Index (SI), port authorities and carrier managers may make policies to improve ship berthing safety at docks. Finally, as an empirical study, the carriers berthing their ships at Kaohsiung port in Taiwan were investigated to validate the model. The rest of this paper is organised as follows. Section 2 reviews the literature. Section 3 explains the research method in this paper. The results are then examined in Section 4. Finally, some general conclusions and limitations for further research are given.

2. LITERATURE REVIEWS. Based on the relevant research and the features of ships' berthing operations, this paper reviews the literature on ship berthing safety from seven dimensions: marine pilot, ship factor, tugboat operation, dock operation, port management, operating staffs' health, and weather and geography.

2.1. Marine pilot. For many ship berthing operations, a marine pilot is often conducting the shiphandling. Thus, the professional skills of the marine pilots may be considered an important determinant of the operations. Further, the workplace of a marine pilot on a vessel is an international environment, where the pilot deals with crews from different cultures that speak different languages. Thus poor communication may lead to crews misunderstanding the pilot's steering order, and as a result, reduce the ship's berthing safety. Therefore, in addition to professional skills, a marine pilot's language ability, and communication ability may also affect ship berthing operations at ports. Previous studies have shown that poor communication between crews and marine pilots was a major factor in marine disasters near ports (Hetherington et al., 2006; Darbra et al., 2007; Hsu, 2012). Further, the language and cultural diversity of seafarers may affect shipping safety (Hetherington. et al., 2006; Knudsen and Hassler, 2011).

2.2. Ship factor. In practice, for ship berthing safety, the ship factor comprises ship staff and berthing equipment condition. The former includes the ship crews' operational skills and work attitudes in cooperating with the pilot; while the latter contains the conditions of equipment such as steering gear and windlasses. Past studies have indicated ship workers' professional skills and work attitudes may affect ship navigation safety (Lu and Tsai, 2008). Feedback from crews to the ship master significantly affect the reporting performance (frequency) of shipping accidents, and so do the interpersonal relationships and communication among crews (Oltedal and McArthur, 2011). A ship crew's improper operation, machinery failure (Darbra et al., 2007) and vessel performance (Liu et al., 2006; Hsu, 2012) may also lead to marine disasters. 
The type, size, age and condition of the vessel at the time of the accident are also important factors (Kokotos and Smirlis, 2005).

2.3. Tugboat operation. The main operations of tugboats are to assist vessels in berthing alongside and departing from docks, including pushing and towing the vessels. The previous studies showed tugboat failure is one of the causes of marine accidents in ports (Darbra et al., 2007). Further, the factors affecting the quality of tugboat operations include the number of tugboats, the horsepower of the tugboat, and the operating skills of the tugboat drivers (Hsu, 2012).

2.4. Dock operation. For ship berthing safety, the dock operation factor contains line handling operation and dock facilities. Relevant studies have indicated the operating skills and work attitudes of linemen may affect ship navigation safety in port (Hsu, 2012). The number of windlasses in the dock and the operating location of the line handling boat (mooring buoy operation) may be another determinant of ship berthing safety (Chiu, 2013). As for the dock facility, in practice, the berth's length should be the most important factor to affect ship berthing safety. Practically, the berth's length should be 1.2 times longer than the berthing vessel (Liu et al., 2006) to provide the vessel enough space for ship mooring operations. However, due to the global development of large-sized ships, the space may frequently be decreased, leading to collisions between neighbouring ships.

2.5. Port management policy. This factor contains two parts:

2.5.1. Port management regulations. To ensure port safety, port authorities may develop related rules to regulate ships' operations in port. For example, in Kaohsiung port, the relevant regulations for ship's berthing operations include: marine pilot laws, ship navigation regulations in port, tugboat operator regulations and line handling operator regulations. Previous studies indicate the safety management system is a determinant of offshore safety (Wang, 2002). However, in practice, those rules or systems may not be completely developed, and the operators may not comply with them perfectly.

2.5.2. Port policy to improve business. In order to increase business, the port authority may allow too many ships to berth simultaneously, increasing the density of ships in ports. This may result in rushed ship berthing operations, which could lead to more ship collisions. Relevant studies indicate ship collision risks increase with the density of ship at a specific water area (Debnath et al., 2011). Further, another policy for improving the port's business is to speed up the logistic operations of terminals. This may result in the berthing operations to be performed hastily, which may also lead to more ship accidents (Hsu, 2012).

2.6. The operating staff's health. The operating staff of a ship's berthing operations include marine pilots, ship crews, tugboat drivers and linesmen. In practice, the staff need to work in shifts. Therefore, their physical and mental health may affect their working concentration, which may influence ship navigation safety (Hsu, 2012). Previous research illustrated there were potentially disastrous outcomes from fatigue in terms of poor health (Josten, et al., 2003; Hetherington, 2006). Shift patterns contribute to fatigue and in turn cause poorer health and safety performance (IskraGolec, et al., 1996).

2.7. Weather and geography. Past studies have indicated weather and geography are common factors leading to shipping accidents (Ugurlu et al., 2014). Hsu et al. (2008) examined the relations between the type of marine casualties and the places that disasters occurred. This revealed the most frequent marine casualties were 


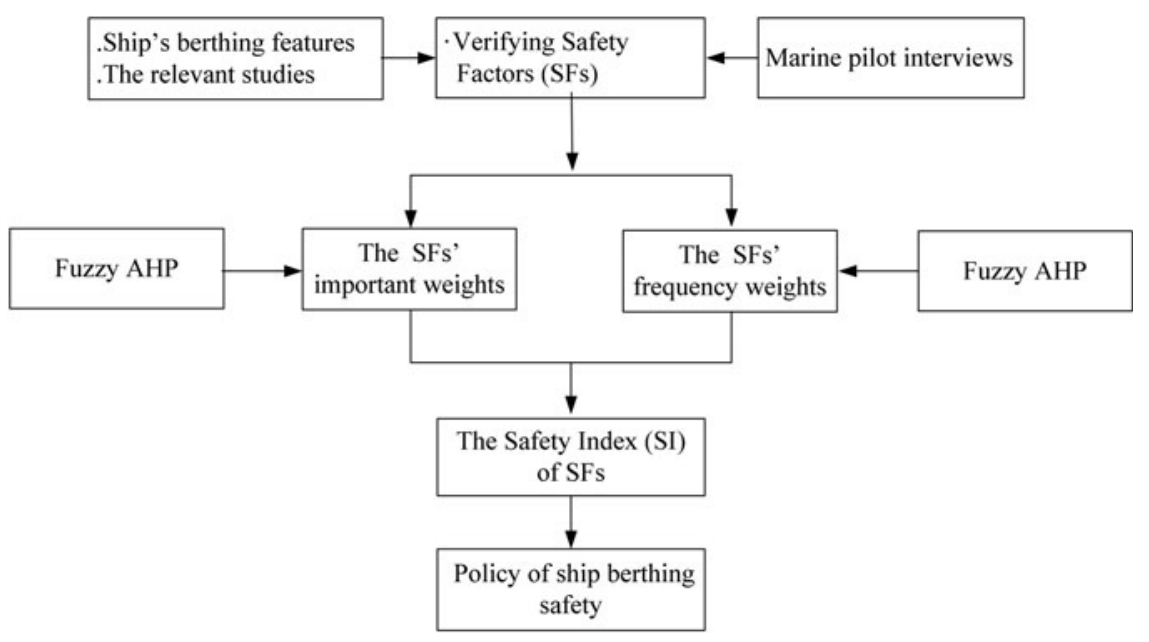

Figure 1. Research framework.

collisions, and the layout of berth and the water area of the port were highly related to collisions and groundings. Kokotos and Smirlis (2005) indicated the weather, sea condition and the location of ship are important factors in predicting ship loss. Ismail and Karim (2013) investigated the cause of tanker spill accidents and concluded storms and hurricanes are the second most common cause of ship accidents $(31 \cdot 8 \%)$ after navigation errors $(42 \cdot 5 \%)$.

\section{RESEARCH METHOD}

3.1. Research Framework. The research framework of this paper is shown in Figure 1. The Safety Factors (SFs) for ships' berthing operations are first investigated. A fuzzy AHP model (Hsu and Huang, 2014) is then proposed to weight both the SFs' importance and frequency degrees. Based on those two weights, a Safety Index (SI) is finally created to assess the ship berthing safety, by which port managers and ship carriers may make policies to improve ship berthing safety at port docks.

3.2. Measurement of safety factors

3.2.1. The definitions of safety factors. Based on the features of ship berthing operations and interviews with several marine pilots, we reorganised the determinants mentioned in previous research, and identified the SFs as four dimensions, in which the weather and geography is not considered for it is a natural factor.

3.2.1.1. Human factor. For ship berthing, the operating staff include the marine pilot, ship crews, tugboat drivers and linesmen. The human factor is defined as the capabilities of the staffs, including professional skill, communication, emergency handling and working concentration.

3.2.1.2. Machinery ( $M E)$. Machinery is defined as the conditions of machines and equipment for ship berthing operations, including the main engine and steering gear of ship, tugboats, deck machines (windlasses) and mooring lines.

3.2.1.3. Port management ( $P M)$. Port management is defined as the completeness and performance of the rules or regulations for ship berthing operations, and 
Table 1. Hierarchical structure of safety factors (SFs) for ship berthing operations.

\begin{tabular}{lll}
\hline Layer 1: Construct & & Layer 2: Safety factors (SFs) \\
\hline Human factors (HF) & HF1 & Professional skills. \\
& HF2 & Communications. \\
& HF3 & Emergency response. \\
MF4 & Working concentration. \\
& ME1 & The conditions of the main engine and steering engine. \\
& ME2 & The number and condition of the tugboats. \\
Port management (PM) & ME4 & The number and condition of the windlasses. \\
& PM1 & The condition of the mooring lines. \\
& PM2 & The completeness of the port's rule and regulations. \\
Port facility (PF) & PM3 & The port policy for improving business. \\
& PF1 & The width and depth of the main channel. \\
& PF2 & The berth's length \\
& PF3 & The shore equipment, such as bollard and pads. \\
\hline
\end{tabular}

the policy for improving the business of the port, such as speeding up the logistical operations, encouraging large ships to stay, etc.

3.2.1.4. Port facility. Port facility is defined as the port equipment for ship berthing operations, including berth length and the conditions and number of bollards and fender pads.

Based on the above definitions, a two-layer hierarchy structure of SFs for ship berthing safety was first constructed. To improve the practical validity of the SFs, three practical marine pilots were then invited to revise those SFs and check if any important SFs were missed. Further, they also checked the independences among those SFs. After several rounds of discussions and revisions, the final hierarchy structure of the SFs, shown in Table 1, contains four dimensions of SFs for the first layer and 14 SFs for the second layer.

3.2.2. Questionnaire design. In this paper, an AHP questionnaire (Saaty, 1980) with a nine point rating scale was designed to measure the marine pilot's perceived "importance" and "frequency" toward each SF respectively. Based on the hierarchical structure of SFs in Table 1, an AHP questionnaire with five criteria and 14 sub-criteria was created. To validate the scale, the questionnaire was then pre-tested by the three previous marine pilots to check if the statements were understandable.

3.2.3. Research Sample. In practice, the marine pilot is the main operator for ship berthing operations. Thus, the marine pilots of Kaohsiung Port were surveyed in this paper. To enhance the validity of the survey, an assistant was dispatched to help the respondents fill out the questionnaire. Currently, there are 42 marine pilots at Kaohsiung Port, from which we surveyed 16 marine pilots randomly and interviewed them in May 2013. For each of the sample, the Consistency Index (CI) was first calculated to test the consistency of its pairwise comparison matrix. The results indicated two samples with CI $>0 \cdot 1$ were highly inconsistent (Saaty, 1980). Therefore, these two questionnaires were discarded. The profiles of the validated 14 respondents' characteristics are shown in Table 2. It shows all of the subjects have at least ten years of experience with over $80 \%$ respondents having over 20 years. Note the remarkable qualifications of the respondents endorse the reliability of the survey findings. 
Table 2. Profile of the respondents.

\begin{tabular}{llll}
\hline Characteristics & Range & Frequency & Percentage (\%) \\
\hline Marine pilot experience at Kaohsiung Port & Under 10 & 2 & $14 \cdot 29$ \\
& $10-15$ & 2 & $14 \cdot 29$ \\
& $16-20$ & 3 & $21 \cdot 43$ \\
Age (years) & Above 20 & 7 & $50 \cdot 00$ \\
& Under 50 & 1 & $7 \cdot 14$ \\
& $51-55$ & 4 & $28 \cdot 57$ \\
Education level & $56-60$ & 5 & $35 \cdot 71$ \\
& Above 60 & 4 & $28 \cdot 57$ \\
& Master & 1 & $7 \cdot 14$ \\
& University & 5 & $35 \cdot 71$ \\
& College & 8 & $57 \cdot 14$ \\
\hline
\end{tabular}

3.3. The weights of safety factors. From the sample data, 14 pairwise comparison matrices were obtained for each comparison of the SFs in each layer. In the past, most relevant studies used the arithmetic mean or geometric mean to integrate multiple subjects' opinions. However, those two means are sensitive to extreme values. Thus, a fuzzy number is considered to integrate the subjects' perceptions in this paper. First, the geometric mean was employed to represent the consensus of respondents (Buckley, 1985; Saaty, 1980). A triangular fuzzy number characterised by minimum, geometric mean and maximum of the measuring scores was then used to integrate the 14 pairwise comparison matrices into a fuzzy positive reciprocal matrix. Based on the fuzzy reciprocal matrices, a fuzzy AHP approach was finally conducted to determine the weights of the SFs, including both of the measurements of important and frequency.

3.3.1. The fuzzy positive reciprocal matrix. Let $\tilde{A}=\left[\tilde{a}_{i j}\right]_{n \times n}$ be a fuzzy positive reciprocal matrix with $n \mathrm{SFs}$, where $\tilde{a}_{i j}=\left[l_{i j}, m_{i j}, u_{i j}\right]$ is a triangular fuzzy number with

$$
\left[l_{i j}, m_{i j}, u_{i j}\right]=\left\{\begin{array}{cc}
{[1,1,1],} & \text { if } i=j \\
{\left[1 / u_{j i}, 1 / m_{j i}, 1 / l_{j i}\right]} & \text { if } i \neq j .
\end{array}\right.
$$

For ease of demonstration, let $A^{(k)}=\left[a_{i j}^{(k)}\right]_{n \times n}, k=1,2, \ldots, m$, denote the pair-wise comparison matrix of $m$ subjects. Then, those $m$ matrices can be integrated into the following fuzzy positive reciprocal matrix:

$$
\tilde{A}=\left[\tilde{a}_{i j}\right]_{n \times n}
$$

where $\tilde{a}_{i j}=\left[\min _{1 \leq k \leq m}\left\{a_{i j}^{(k)}\right\},\left(\prod_{k=1}^{m} a_{i j}^{(k)}\right)^{1 / m}, \max _{1 \leq k \leq m}\left\{a_{i j}^{(k)}\right\}\right]$ is a triangular fuzzy number, $i=1,2, \ldots, n, j=1,2, \ldots, n$ and $k=1,2, \ldots, m$.

3.3.2. The consistency tests. Before calculating the weights of the SFs in the fuzzy positive reciprocal matrix $(\tilde{A})$, an immediate problem is to test the consistency of $\tilde{A}$. The problem results from the fact that the criteria (SFs) within the $\tilde{A}$ are fuzzy numbers, so the consistency of $\tilde{A}$ cannot be tested directly as a traditional AHP. Buckley (1985) conducted the consistency test for a fuzzy positive reciprocal matrix whose criteria are trapezoidal fuzzy numbers. He first used the geometric means to 
Table 3. The randomized index (RI)

\begin{tabular}{lllllllllll}
\hline$n$ & 3 & 4 & 5 & 6 & 7 & 8 & 9 & 10 & 11 & 12 \\
\hline R.I. & 0.58 & 0.90 & 1.12 & 1.24 & 1.32 & 1.41 & 1.45 & 1.49 & 1.52 & 1.54 \\
\hline
\end{tabular}

defuzzify the criteria and thus convert the fuzzy positive reciprocal matrix into a crisp matrix. Then, the consistency test can be undertaken for the crisp matrix, as traditional AHP. In this paper, we use the method of Buckley (1985) to defuzzify the $\tilde{A}$. Specifically, for the positive reciprocal matrix $\tilde{A}$, the fuzzy numbers $\tilde{a}_{i j}=\left[l_{i j}, m_{i j}, u_{i j}\right]$ can be defuzzified as:

$$
a_{i j}=\left(l_{i j} \cdot m_{i j} \cdot m_{i j} \cdot u_{i j}\right)^{1 / 4}, i=1,2, \ldots, n, j=1,2, \ldots, n
$$

Generally, the following CI (Consistency Index) and CR (Consistency Ratio) are the two indices used to test the consistency of a crisp positive reciprocal matrix in traditional AHP:

$$
\mathrm{CI}=\frac{\lambda_{\max }-n}{n-1}
$$

and

$$
\mathrm{CR}=\frac{\mathrm{CI}}{\mathrm{RI}}
$$

where $\lambda_{\max }$ is the maximum eigenvalue of the positive reciprocal matrix and $n$ is the number of criteria in the matrix. The RI represents a randomized index, whose values are shown in Table 3 (Hsu and Huang, 2014). Saaty (1980) suggested that a value for $\mathrm{CR} \leq 0.1$ is an acceptable range for consistency test of the crisp positive reciprocal matrix.

In our sample data, the results of consistency tests are listed in Table 4. Since all of the C.R. indices in Table 4 are less than $0 \cdot 1$, all of the positive reciprocal matrixes in the sample data are consistent.

3.3.4. The local weights of SFs. The local weights of SFs can be determined from the eigenvectors of matrix $\tilde{A}$. However, due to the special structure of the positive reciprocal matrix, Saaty (1980) suggested four methods to find the eigenvectors: Average of Normalized Columns (ANC), Normalization of the Row Average (NRA), Normalization of the Reciprocal of Columns Sum (NRCS) and Normalization of the Geometric Mean of the Rows (NGMR). Since the MGM method was applied most popularly in previous studies, this paper adopts the MGM to determine the local weights of SAs in matrix $\tilde{A}$.

For the fuzzy positive reciprocal matrix $\tilde{A}$, the geometric means of the triangular fuzzy numbers for the $i$ th $\mathrm{SF}(i=1,2, \ldots, n)$ can be found as:

$$
\tilde{w}_{i}=\left(\prod_{j=1}^{n} \tilde{a}_{i j}\right)^{1 / n}=\left[\left(\prod_{j=1}^{n} l_{i j}\right)^{1 / n},\left(\prod_{j=1}^{n} m_{i j}\right)^{1 / n},\left(\prod_{j=1}^{n} u_{i j}\right)^{1 / n}\right], i=1,2, \ldots, n .
$$


Table 4. The results of the consistency tests.

\begin{tabular}{lllll}
\hline Shipmaster's perceptions & Layer & CI & RI & CR (CI/RI) \\
\hline Importance & Layer 1 & $0 \cdot 076$ & $1 \cdot 115$ & $0 \cdot 068$ \\
& Layer2: HF & $0 \cdot 085$ & $0 \cdot 882$ & $0 \cdot 096$ \\
& Layer2: ME & $0 \cdot 071$ & $0 \cdot 882$ & $0 \cdot 080$ \\
& Layer2: PM & $0 \cdot 028$ & $0 \cdot 525$ & $0 \cdot 053$ \\
& Layer2: DF & $0 \cdot 053$ & $0 \cdot 882$ & $0 \cdot 060$ \\
Dissatisfaction & Layer 1 & $0 \cdot 054$ & $1 \cdot 115$ & $0 \cdot 048$ \\
& Layer2: HF & $0 \cdot 034$ & $0 \cdot 882$ & $0 \cdot 039$ \\
& Layer2: ME & $0 \cdot 021$ & 0.882 & $0 \cdot 024$ \\
& Layer2: PM & $0 \cdot 035$ & 0.882 & $0 \cdot 040$ \\
& Layer2: DF & $0 \cdot 019$ & $0 \cdot 882$ & $0 \cdot 022$ \\
\hline
\end{tabular}

From Equation (5), we have:

$$
\sum_{i=1}^{n} \tilde{w}_{i}=\left[\sum_{i=1}^{n}\left(\prod_{j=1}^{n} l_{i j}\right)^{1 / n}, \sum_{i=1}^{n}\left(\prod_{j=1}^{n} m_{i j}\right)^{1 / n}, \sum_{i=1}^{n}\left(\prod_{j=1}^{n} u_{i j}\right)^{1 / n}\right] .
$$

Also, from Equations (5) and (6), the fuzzy weight of the $i$ th $\mathrm{SF}(i=1,2, \ldots, n)$ can then be obtained as:

$$
\widetilde{W}_{i}=\tilde{w}_{i} / \sum_{i=1}^{n} \tilde{w}_{i}=\left[\frac{\left(\prod_{j=1}^{n} l_{i j}\right)^{1 / n}}{\sum_{i=1}^{n}\left(\prod_{j=1}^{n} u_{i j}\right)^{1 / n}}, \frac{\left(\prod_{j=1}^{n} m_{i j}\right)^{1 / n}}{\sum_{i=1}^{n}\left(\prod_{j=1}^{n} m_{i j}\right)^{1 / n}}, \frac{\left(\prod_{j=1}^{n} u_{i j}\right)^{1 / n}}{\sum_{i=1}^{n}\left(\prod_{j=1}^{n} l_{i j}\right)^{1 / n}}\right], i=1,2, \ldots, n
$$

3.3.5. The defuzzification process. Since the local weight, $\widetilde{W}_{i}$, of the $i$ th $\mathrm{SF}(i=1$, $2, \ldots, n)$ is fuzzy, this paper uses Yager's index (1981) to defuzzify the $\widetilde{W}_{i}$ into a crisp number $W_{i}, i=1,2, \ldots, n$. For convenience of explanation, let $\widetilde{W}_{i}=\left[l_{i}^{W}, m_{i}^{W}, u_{i}^{W}\right]$, where

$$
\left[l_{i}^{W}, m_{i}^{W}, u_{i}^{W}\right]=\left[\frac{\left(\prod_{j=1}^{n} l_{i j}\right)^{1 / n}}{\sum_{i=1}^{n}\left(\prod_{j=1}^{n} u_{i j}\right)^{1 / n}}, \frac{\left(\prod_{j=1}^{n} m_{i j}\right)^{1 / n}}{\sum_{i=1}^{n}\left(\prod_{j=1}^{n} m_{i j}\right)^{1 / n}}, \frac{\left(\prod_{j=1}^{n} u_{i j}\right)^{1 / n}}{\sum_{i=1}^{n}\left(\prod_{j=1}^{n} l_{i j}\right)^{1 / n}}\right], i=1,2, \ldots, n .
$$

Then, the $\widetilde{W}_{i}, i=1,2, \ldots, n$ can be defuzzified as:

$$
W_{i}=\left(l_{i}^{W}+2 m_{i}^{W}+u_{i}^{W}\right) / 4, i=1,2, \ldots, n .
$$

Finally, normalizing the $W_{i}(i=1,2 . ., n)$, the crisp local weight of the $i$ th SFs can be obtained as:

$$
\bar{\omega}_{i}=W_{i} / \sum_{i=1}^{n} W_{i}, i=1,2, \ldots, n
$$


Table 5. The importance weights (IWs) of safety factors for ship berthing operations.

\begin{tabular}{lllll}
\hline $\begin{array}{l}\text { Layer 1: } \\
\text { SFs }\end{array}$ & $\begin{array}{l}\text { The global weights of } \\
\text { Layer 1 SFs (\%) }\end{array}$ & $\begin{array}{l}\text { Layer 2: } \\
\text { SFs }\end{array}$ & $\begin{array}{l}\text { The local weights of } \\
\text { Layer 2 SFs (\%) }\end{array}$ & $\begin{array}{l}\text { The global weights of } \\
\text { Layer 2 SFs (\%) }\end{array}$ \\
\hline HF & $32 \cdot 19$ & HF1 & $28 \cdot 076$ & $\mathbf{9 \cdot 0 4}$ \\
& & HF2 & $20 \cdot 264$ & $6 \cdot 52$ \\
& & HF3 & $26 \cdot 797$ & $\mathbf{8 \cdot 6 3}$ \\
ME & \multirow{2}{*}{$29 \cdot 04$} & HF4 & $24 \cdot 863$ & $\mathbf{8 \cdot 0 0}$ \\
& & ME1 & $29 \cdot 523$ & $\mathbf{8 \cdot 5 7}$ \\
& & ME2 & $21 \cdot 047$ & $6 \cdot 11$ \\
PM & \multirow{2}{*}{$20 \cdot 24$} & ME3 & $23 \cdot 117$ & $6 \cdot 71$ \\
& & ME4 & $26 \cdot 313$ & $7 \cdot 64$ \\
& & PM1 & $33 \cdot 225$ & $6 \cdot 72$ \\
DF & \multirow{2}{*}{$18 \cdot 53$} & PM2 & $31 \cdot 748$ & $6 \cdot 43$ \\
& & PM3 & $35 \cdot 027$ & $7 \cdot 09$ \\
& & DF1 & $35 \cdot 190$ & $6 \cdot 52$ \\
& & DF2 & $34 \cdot 195$ & $6 \cdot 34$ \\
\hline
\end{tabular}

Note: The boldfaced numbers represent the SFs with higher weights.

3.3.6. The global weights of the SFS. By the above steps in Sections $3 \cdot 3 \cdot 2 \sim 3 \cdot 3 \cdot 5$, we can find all the local weights of the SFs in Table 5. The global weights of the SFs can then be found by multiplying their low level of local weights by their corresponding high level of global weights. Table 5 shows the results of all global weights of the SFs for the importance measurement of sample data. The global weights of the SFs in the first layer are shown in the second field, and those of the SFs in the second layer are shown in the last field. Likewise, the global weights of SFs for the frequency measurement of sample data are shown in Table 6.

3.4. The Safety Index of SFs. Obviously, a SF with higher degrees of importance and frequency should be improved with higher priority. Based on such a concept, a Safety Index (SI) was proposed to determine the SFs' priorities. Let $I W_{i}^{n}$ and $F W_{i}^{n}$ denote the weights of the importance weight and frequency weight of the $i$ th SF $(i=1,2, \ldots, n)$, which are obtained from Tables 5 and 6 , respectively. Then, the SI of the $i$ th SF is defined as:

$$
S I_{i}=\left(I W_{i}^{n} * F W_{i}^{n}\right) / \sum_{i=1}^{n}\left(I W_{i}^{n} * F W_{i}^{n}\right), i=1,2, \ldots, n
$$

For our sample, the SI indexes are shown in the fourth and the last fields of Table 7, in which the higher SI values are highlighted in boldface. Table 7 shows, for the first layer of SFs, the HF (Human Factor) construct has the highest SI; while for the second layer of SFs, the top four SFs with higher SI are HF4, ME2, HF3 and DF2.

\section{RESULTS AND IMPLICATIONS}

4.1. The importance weights of SFs. The results of Table 5 indicate, overall, the Human Factor (HP, 32.19\%) is the most important construct to affect ship berthing safety. While, the top five SFs by importance weights are: HF1 (Professional skills, 9.04\%), HF3 (Emergency response, 8.63\%), ME1 (The conditions of main engine 
Table 6. The frequency weights (FWs) of safety factors for ship berthing operations.

\begin{tabular}{|c|c|c|c|c|}
\hline Layer 1: SFs & $\begin{array}{l}\text { The global weights } \\
\text { of Layer } 1 \text { SFs (\%) }\end{array}$ & Layer 2: SFs & $\begin{array}{l}\text { The local weights of } \\
\text { Layer } 2 \text { SFs }(\%)\end{array}$ & $\begin{array}{l}\text { The global weights } \\
\text { of Layer } 2 \text { SFs ( } \%)\end{array}$ \\
\hline $\mathrm{HF}$ & $39 \cdot 69$ & $\begin{array}{l}\text { HF1 } \\
\text { HF2 } \\
\text { HF3 } \\
\text { HF4 }\end{array}$ & $\begin{array}{l}6 \cdot 46 \\
14 \cdot 72 \\
24 \cdot 04 \\
54 \cdot 79\end{array}$ & $\begin{array}{l}2 \cdot 56 \\
5 \cdot 84 \\
9 \cdot 54 \\
\mathbf{2 1} \cdot \mathbf{7 5}\end{array}$ \\
\hline $\mathrm{ME}$ & $24 \cdot 90$ & $\begin{array}{l}\text { ME1 } \\
\text { ME2 } \\
\text { ME3 } \\
\text { ME4 }\end{array}$ & $\begin{array}{l}26 \cdot 39 \\
4 \cdot 96 \\
13 \cdot 41 \\
55 \cdot 24\end{array}$ & $\begin{array}{l}6 \cdot 57 \\
1 \cdot 24 \\
3 \cdot 34 \\
\mathbf{1 3 \cdot 7 5}\end{array}$ \\
\hline PM & $16 \cdot 02$ & $\begin{array}{l}\text { PM1 } \\
\text { PM2 } \\
\text { PM3 }\end{array}$ & $\begin{array}{l}9 \cdot 14 \\
21 \cdot 76 \\
69 \cdot 10\end{array}$ & $\begin{array}{l}1 \cdot 46 \\
3 \cdot 49 \\
\mathbf{1 1 \cdot 0 7}\end{array}$ \\
\hline DF & $19 \cdot 39$ & $\begin{array}{l}\text { DF1 } \\
\text { DF2 } \\
\text { DF3 }\end{array}$ & $\begin{array}{l}23 \cdot 85 \\
62 \cdot 50 \\
13 \cdot 65\end{array}$ & $\begin{array}{l}4 \cdot 62 \\
\mathbf{1 2} \cdot \mathbf{1 2} \\
2 \cdot 65\end{array}$ \\
\hline
\end{tabular}

Note: The boldfaced numbers represent the SFs with higher weights.

Table 7. The Safety Index (SI) of safety factors for ship berthing operations.

\begin{tabular}{|c|c|c|c|c|c|c|c|}
\hline $\begin{array}{l}\text { Layer 1: } \\
\text { SFs }\end{array}$ & $\begin{array}{l}\text { Importance } \\
(\%)\end{array}$ & $\begin{array}{l}\text { Frequency } \\
(\%)\end{array}$ & $\begin{array}{l}\text { Layer1: SI } \\
(\%)\end{array}$ & $\begin{array}{l}\text { Layer 2: } \\
\text { SFs }\end{array}$ & $\begin{array}{l}\text { Importance } \\
(\%)\end{array}$ & $\begin{array}{l}\text { Frequency } \\
(\%)\end{array}$ & $\begin{array}{l}\text { Layer 2: } \\
\text { SI }(\%)\end{array}$ \\
\hline $\mathrm{HF}$ & $32 \cdot 19$ & 39.69 & $47 \cdot 60$ & $\begin{array}{l}\text { HF1 } \\
\text { HF2 } \\
\text { HF3 } \\
\text { HF4 }\end{array}$ & $\begin{array}{l}\mathbf{9 \cdot 0 4} \\
6 \cdot 52 \\
\mathbf{8 \cdot 6 3} \\
\mathbf{8 \cdot 0 0}\end{array}$ & $\begin{array}{l}2 \cdot 56 \\
5 \cdot 84 \\
9 \cdot 54 \\
\mathbf{2 1} \cdot 75\end{array}$ & $\begin{array}{l}3 \cdot 12 \\
5 \cdot 14 \\
\mathbf{1 1} \cdot 10 \\
\mathbf{2 3} \cdot \mathbf{4 6}\end{array}$ \\
\hline ME & $29 \cdot 04$ & $24 \cdot 90$ & 26.94 & $\begin{array}{l}\text { ME1 } \\
\text { ME2 } \\
\text { ME3 } \\
\text { ME4 }\end{array}$ & $\begin{array}{l}8 \cdot 57 \\
6 \cdot 11 \\
6 \cdot 71 \\
7 \cdot 64\end{array}$ & $\begin{array}{l}6 \cdot 57 \\
1 \cdot 24 \\
3 \cdot 34 \\
\mathbf{1 3} \cdot \mathbf{7 5}\end{array}$ & $\begin{array}{l}7 \cdot 60 \\
1 \cdot 02 \\
3 \cdot 02 \\
\mathbf{1 4 \cdot 1 7}\end{array}$ \\
\hline PM & $20 \cdot 24$ & $16 \cdot 02$ & $12 \cdot 08$ & $\begin{array}{l}\text { PM1 } \\
\text { PM2 } \\
\text { PM3 }\end{array}$ & $\begin{array}{l}6 \cdot 72 \\
6 \cdot 43 \\
7 \cdot 09\end{array}$ & $\begin{array}{l}1 \cdot 46 \\
3 \cdot 49 \\
\mathbf{1 1} \cdot 07\end{array}$ & $\begin{array}{l}1 \cdot 33 \\
3 \cdot 02 \\
\mathbf{1 0} \cdot 58\end{array}$ \\
\hline $\mathrm{DF}$ & $18 \cdot 53$ & $19 \cdot 39$ & $13 \cdot 39$ & $\begin{array}{l}\text { DF1 } \\
\text { DF2 } \\
\text { DF3 }\end{array}$ & $\begin{array}{l}6 \cdot 52 \\
6 \cdot 34 \\
5 \cdot 67\end{array}$ & $\begin{array}{l}4 \cdot 62 \\
\mathbf{1 2 \cdot 1 2} \\
2 \cdot 65\end{array}$ & $\begin{array}{l}4 \cdot 07 \\
\mathbf{1 0 \cdot 3 5} \\
2 \cdot 02\end{array}$ \\
\hline
\end{tabular}

Note: The boldfaced numbers represent the SFs with higher weights.

and steering engine, $8 \cdot 57 \%$ ) and HF4 (Working concentration, 8.00\%). The results imply the human factor (HF1, HF3 and HF4) could be the main determinant of the ship berthing safety. This result confirms previous relevant studies showing that the human factor is the most important determinant of vessel accidents in container shipping context (Lu and Tsai, 2008; Tzannatos and Kokotos, 2009), shipping safety in restricted waters (Kokotos and Linardatos, 2011) and ship navigation in port (Hsu, 2012).

Practically, the main operating staff for ship berthing operations in port include marine pilots, ship crews, tugboat drivers and linesmen. Thus, for improving ship's berthing safety, port authorities may focus on strengthening those staffs' training 
levels. In practice, most vessel accidents occur in an instant. Thus, the response capability for emergencies is particularly important for those staff. For enhancing their response capability in emergencies, this paper suggests the port authority may make policy to encourage or even mandatorily require staff to attend related training activities regularly, such as experience sharing, computer simulation for berthing operations, analysis of the causes of collisions, and how to prevent accidents etc. Further, the port authority may also make a license system to force those staff to participate in training.

Further, in practice, the operating staff's mental and physical condition on duty is the main determinant of their working concentration. Generally, all of the staff have to work night shifts, which may lead to mental fatigue and decrease their working concentration. Relevant studies indicated human fatigue is one of the main causes of marine casualties (Josten et al., 2003; Hetherington, 2006). This paper suggests the port authority may make regulations to control the shift system of operating staff, such as the maximum work hours for a shift.

4.2. The Safe Indexes of SFs for Kaohsiung port. The result of the Safety Index (SI) for Kaohsiung Port, shown in Table 7, indicated the top five SFs with higher SI are: HF4 (Working concentration, 23.46\%), ME4 (The condition of mooring lines, $14 \cdot 17 \%$ ), HF3 (Emergency response, 11.10\%), PM3 (The port policy for improving business, 10.58\%) and DF2 (The berth's length, 10.35\%). Since the SF's Safety Index (SI) consists of importance weight and frequency weight, the SI may reveal the management performance of port authority and ship carriers. Based on the results, we conducted post-interviews with several of the surveyed marine pilots and made some suggestions for the Kaohsiung port authority and carrier managers.

4.2.1. Improving operating staff's work training levels. As explained in Section 4.1, several policies may be considered for Kaohsiung port authority and carrier managers to enhance their operating staff's work training levels such as holding related training activities, making a license system and improving the shift system.

4.2.2. Improving port's business policy. In practice, port authorities may adopt policies to improve their port's business, such as utilising terminals, speeding up logistical operations of terminals, etc. However, those policies may reduce the operating time of ship berthing, leading to more ship accidents. Thus, balancing business demands and ship safety is an important problem for port managers to consider. This paper suggests port authorities may set an upper limit to control the ship density in port, by which the operating staff may have sufficient time to berth their ships, and to ensure their safety.

5. CONCLUSION. Relevant statistics indicate collisions are the most frequent maritime accident. In practice, collisions most frequently occur when ships berth in port. However, previous studies discuss such topics less. In this paper, a Safety Index (SI) with a fuzzy AHP model was proposed to assess the safety factors (SFs) of ship's berthing operations at dock. The Safety Index consists of both SFs' importance and frequency weights, not only indicating the SF's priorities, but also the performance of port management. Compared with the previous literature, the SI may provide more complete information for port authorities and carrier managers to improve their ship berthing safety at docks. The proposed model may provide theoretical references for further research on methodology and ship navigation safety. 
For validating the practical application of the proposed model, ship berthing operations at Kaohsiung Port in Taiwan were empirically investigated. The results indicated operating staff training level is the most important determinant of ship berthing safety. In practice, the main operating staff of a port include marine pilots, ship crews, tugboat drivers and linesmen. Thus, those staffs' personal training levels should be enhanced, including professional skills, emergency response and working concentration. Further, for Kaohsiung port, in addition to operating staffs' work training levels, the port authority and carrier managers also need to pay more attention to the problems of regulating mooring lines and balancing business demands and ship safety. The results may provide practical information for Kaohsiung port and other port authorities to make policies in improving their ship berthing safety.

In this paper, the Safety Index consists of both SFs' importance and frequency weights. In fact, the Safety Index is similar to the assessment of risk factors in a Risk Matrix Model (RMM), which contains two risk coefficients: risk severity and risk frequency (Shang and Tseng, 2010; Yang, 2010, Tseng et al, 2012). Since, in the pre-test period, the respondents argued that severity measurement is difficult to evaluate in ship accidents, this paper adopted "importance" instead of "severity". However, risk assessment is a popular method for safety assessment of an organisation. Thus it could be a topic for ship berthing safety in further research. Furthermore, in this paper, 14 marine pilots at Kaohsiung Port in Taiwan were empirically surveyed to validate the proposed model. To enhance the validity of the questionnaire investigation, this paper adopted an interview survey instead of a mailed survey. Thus, the validity and reliability of the findings in this paper could be endorsed. However, for better confirmation of the empirical results, more representative samples may be necessary in future research.

\section{ACKNOWLEDGEMENT}

The author is grateful to Mrs C.F. Chiu for her assistance in data collection and the anonymous reviewers for their very valuable comments.

\section{REFERENCES}

Buckley, J.J. (1985). Fuzzy hierarchical analysis. Fuzzy Sets and Systems, 17(3), 233-247.

Chiu, C.F. (2013). Safety determinants of ship berthing at port docks (Master's thesis). National Kaohsiung Marine University, Kaohsiung, Taiwan.

Darbra, R.M., Crawford, J.F.E., Haley, C.W and Morrison, R.J. (2007). Safety culture and hazard risk perception of Australian and New Zealand maritime pilots. Marine Policy, 31, 736-745.

Debnath, A.K. and Chin, H.C. (2010). Navigational traffic conflict technique: A proactive approach to quantitative measurement of collision risks in port waters. Journal of Navigation, 63(1), 137-152.

Debnath, A.K., Chin, H.C. and Haque, M.M. (2011). Modelling port water collision risk using traffic conflicts. Journal of Navigation, 64(4), 645-655.

Hetherington, C., Flin, R. and Mearns, K. (2006). Safety in shipping: The human element. Journal of Safety Research, 37, 401-411.

Hsu, K.Y., Chang, Y.C. and Chou, H.P. (2008). An analysis of marine casualties of the international commercial port on the west coast of Taiwan. Maritime Quarterly, 17 (1), 45-62.

Hsu, W.K. (2012). Ports' service attributes for ship navigation safety. Safety Science, 50(2), 244-252. 
Hsu, W.K and Huang, S.H. (2014) Evaluating the service requirements of Taiwanese international port distribution centres using IPA model based on fuzzy AHP. International Journal of Shipping and Transport Logistics, 6(6), 632-651

Ismail, Z. and Karim, R. (2013). Some technical aspects of spills in the transportation of petroleum materials by tankers. Safety Sciences, 51(2), 202-208.

IskraGolec, I., Folkard, S.T.M. and Noworol, C. (1996). Health, well-being and burnout of ICU nurses on 12- and 8-h shifts. Work and Stress, 10(3), 251-256.

Josten, E.J.C., Ng-A-Tham, J.E.E. and Thierry, H. (2003). The effects of extended workdays on fatigue, health, performance and satisfaction in nursing. Journal of Advanced Nursing, 44(6), 643-652.

Knudsen, O.F. and Hassler, B. (2011). IMO legislation and its implementation: Accident risk, vessel deficiencies and national administrative practices. Marine Policy, 35(2), 201-207.

Kokotos, D.X. and Smirlis, G.Y. (2005). A classification tree application to predict total ship loss. Journal of Transportations and Statistics, 8(2), 31-42.

Kokotos, D.X. and Linardatos, D.S. (2011). An application of data mining tools for the study of shipping safety in restricted waters. Safety Sciences, 49, 192-197.

Liu, C.P., Liang, G. S., Su, Y. and Chu, C.W. (2006). Navigation safety Analysis in Taiwanese ports. Journal of Navigation, 59(2), 201-211.

Lu, C.S. and Tsai, C.L. (2008). The effects of safety climate on vessel accidents in container shipping context. Accident Analysis and Prevention, 40(2), 594-601.

Oltedal, H.A. and McArthur, D.P. (2011). Reporting practices in merchant shipping, and the identification of influencing factors. Safety Sciences, 49, 331-338.

Saaty, T.L. (1980). The Analytic Hierarchy Process. McGraw-Hill Companies, Inc., New York.

Shang, K.C. and Tseng, W.J. (2010). A Risk Analysis of Stevedoring Operations in Seaport Container Terminals. Journal of Marine Science and Technology, 18(2), 201-210.

Tseng, W.J., Ding, J.F., Chou, C.C., Hsu, F.T., Wang, Y.M., Liu, Y.N., Chang, N.W. and Wu, Y.W. (2012). Risk Analysis of Cargos Damages for Aquatic Products of Refrigerated Containers: Shipping Operators' Perspective in Taiwan. Information Management and Business Review, 4(2), 86-94.

Tzannatos, E.R. and Kokotos, D.X. (2009). Analysis of accidents in Greek shipping during the pre-and postISM period. Marine Policy, 33(4), 679-684.

Ugurlu, Ö., Kose, E., Yildirim, U. and Yuksekyildiz, E. (2014). Marine accident analysis for collision and grounding in oil tanker using FTA method. Maritime policy and management, DOI:10·1080/ 03088839·2013·856524. (Forthcoming)

Wang, J. (2002). Offshore safety case approach and formal safety assessment of ships. Journal of Safety Research, 33, 81-115.

Yager, R.R. (1981). A Procedure for ordering fuzzy subsets of the unit interval. Information Sciences, 24, $143-161$.

Yang, Y.C. (2010). Impact of the Container Security Initiative on Taiwan's Shipping Industry. Maritime Policy and Management, 37(7), 699-722. 